\title{
Sepsis: are we tackling it right?
}

\author{
de Lanerolle $\mathbf{M} \mathbf{I}^{1}$, Samaranayake $\mathbf{W} \mathbf{R}^{2}$, Ranatunga $\mathbf{K}^{3}$ \\ Journal of the Ceylon College of Physicians, 2017, 48, 34-40
}

\section{Introduction}

Sepsis is a global health challenge of growingincidence, ${ }^{1,2}$ associated with high morbidity and mortality ${ }^{3,4}$.

Considerable advances have been made in the understanding of pathophysiology and management of sepsis in the past two decades. Clinicians should appreciate that sepsis is not a specific illness but a syndrome that may present in a variety of clinical settings. The affected individuals can be diverse in age, comorbidity, concurrent injuries including surgery, medications and the source and type of infection ${ }^{5,6}$. There is no gold standard for the diagnosis of sepsis. A new definition with criteria for early detection of sepsis named "sepsis 3" was released by the Society of Critical Care Medicine (SCCM) and European Society of Intensive Care Medicine (ESICM)in February 2016. Although this is the most updated attempt at early recognition of sepsis, we must be mindful that periodic updating based on new insights is imperative.

\section{Pathophysiology}

The pathophysiology of sepsis is a complex interaction of microbial organism and host immune response involving inflammatory and coagulation pathways.

\section{Role of the immune system}

The immune system is activated by microbial cell wall products, resulting in a complex series of cellular and humoral responses. This results in the release of reactive oxygen free radicles, nitric oxide (NO), pro-teases, and pore-forming molecules that are bactericidal ${ }^{7}$ while unwanted effects occur due to sepsis induced mitochondrial dysfunction ${ }^{8}$, such as vasodilatation and increased capillary permeability.

\footnotetext{
${ }^{1}$ Senior Registrar in Emergency Medicine

${ }^{2}$ Senior Registrar in Critical Care Medicine

${ }^{3}$ Senior Consultant Cardio-thoracic Anaesthesiologist and Intensivist
}

Corresponding author: Ranatunga $\mathrm{K}$

E-mail: ranatungakumari@gmail.com

\section{The endothelium and coagulation system}

The vascular endothelium plays a major role in the host defence to invading organisms, with the resulting endothelial changes causing tissue oedema. Procoagulant factors are increased and natural anticoagulants, which play an anti-inflammatory and modulatory role are reduced ${ }^{9}$.

\section{Inflammation, organ dysfunction and shock}

Relative and absolute hypovolaemia due to vasodilatation and increased capillary permeability are compounded by reduced left ventricular contractility that result in hypotension followed by tissue hypoperfusion and shock. Cellular energy levels fall as metabolic activity begins to exceed production. However, cell death appears to be uncommon in sepsis, implying that cells shut down as part of the systemic response. This explains why sparse histological changes are found at autopsy and the rapid resolution of severe organ dysfunction such as anuria and hypotension, once the systemic inflammation resolves $^{10}$.

\section{Evolution of the definitions of sepsis}

Sepsis exists on a continuum of severity ranging from infection and bacteraemia to sepsis and septic shock, which can lead to multiple organ dysfunction syndrome (MODS) and death. The definitions of sepsis and septic shock have evolved since the early 1990s. The common problem encountered by all consensus definitions is maintaining sensitivity without affecting specificity $^{3}$. Some critics claim that high sensitivity is preferred over specificity considering the severity of the problem ${ }^{11}$. Narrowing the criteria will reduce sensitivity, which leads to a greater risk for delayed diagnosis, which is a major concern especially for low and middle income countries.

\section{Sepsis 1}

In 1991 the first consensus conferenceon sepsis defined it as "a systemic inflammatory response (SIRS) to a new infection." This cornerstone definition mandated the presence of presumed or confiirmed infection and

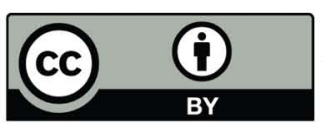

This is an open-access article distributed under the terms of the Creative Commons Attribution License, which permits unrestricted use, distribution, and reproduction in any medium, provided the original author and source are credited. 
presence of two of four SIRS criteria. Sepsis complicated by organ dysfunction was termed severe sepsis, which could progress to septic shock, defined as "sepsisinduced hypotension persisting despite adequate fluid resuscitation"12.

The SIRS criteria are no longer included in the new definitions as it is not always caused by an infection. Kaukonen et al reported based on a large review that SIRS criteria missed one in eight septic patients in the $I^{1 C U^{13}}$.

\section{Sepsis 2}

In 2001, the International Sepsis Definitions Task Force, expanded the list of diagnostic criteria for sepsis, severe sepsis and septic shock but did not offer alternative definitions due to lack of supporting evidence. For example, the diagnosis of sepsis was based on the presence of documented or suspected infection along with the presence of the following variables: general, inflammatory, hemodynamic, tissue perfusion and organ dysfunction ${ }^{14}$.
The major limitation of both these definitions and diagnostic criteria was an excessive focus on inflammation and a misleading model which assumed that sepsis follows a continuum through severe sepsis to shock. The definitions of sepsis, septic shock, and organ dysfunction have remained largely unchanged for more than 2 decades.

\section{Sepsis 3}

In 2016 the SCCM / ESICM convened a task force for the Third International Consensus Definitions on Sepsis ${ }^{15}$.

- "Sepsis is now defined as a life-threatening organ dysfunction caused by a dysregulated host response to infection."

Clinically, organ dysfunction is identified as an acute change in total Sequential Organ Failure Score (SOFA) $\geq 2$ points consequent to an infection.

Table 1. SOFA Score ${ }^{\star}$

\begin{tabular}{|c|c|c|c|c|c|}
\hline \multirow{2}{*}{$\begin{array}{l}\text { 圆 } \\
\text { Variables }\end{array}$} & \multicolumn{5}{|c|}{ SOFA? Score } \\
\hline & 0 & 1 & 2 & 3 & 4 \\
\hline $\begin{array}{l}\text { Respiration - } \\
\mathrm{PaO}_{2} / \mathrm{FIO}_{2}, \mathrm{~mm} \mathrm{Hg}\end{array}$ & $>400$ & $\leq 400$ & $\leq 300$ & $\leq 200^{\mathrm{a}}$ & $\leq 100^{a}$ \\
\hline $\begin{array}{l}\text { Coagulation - } \\
\text { Platelets } \times 10^{3} / \mu \mathrm{L}^{\mathrm{b}}\end{array}$ & $>150$ & $\leq 150$ & $\leq 100$ & $\leq 50$ & $\leq 20$ \\
\hline $\begin{array}{l}\text { Liver - } \\
\text { Bilirubin, } \mathrm{mg} / \mathrm{dL}^{\mathrm{b}}\end{array}$ & $<1.2$ & $1.2-1.9$ & $2.0-5.9$ & $6.0-11.9$ & $>12.0$ \\
\hline $\begin{array}{l}\text { Haemodynamics - } \\
\text { Hypotension }\end{array}$ & $\begin{array}{l}\text { No } \\
\text { hypotension }\end{array}$ & $\begin{array}{l}\text { MAP } \\
<70 \mathrm{~mm} \mathrm{Hg}\end{array}$ & 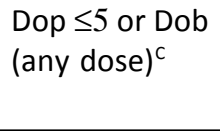 & $\begin{array}{l}\text { Dop }>5, \text { Adr. } \\
\leq 0.1 \text {, or Norad. } \\
\leq 0.1^{c}\end{array}$ & $\begin{array}{l}\text { Dop }>15, \text { Adr. } \\
\leq 0.1 \text {, or Norad } \\
\leq 0.1^{c}\end{array}$ \\
\hline $\begin{array}{l}\text { Central nervous } \\
\text { system - } \\
\text { Glasgow Coma } \\
\text { Scale }\end{array}$ & 15 & $13-14$ & $10-12$ & $6-9$ & $<6$ \\
\hline $\begin{array}{l}\text { Renal - } \\
\text { Creatinine, } \mathrm{mg} / \mathrm{dL}^{\mathrm{d}} \\
\text { or urine output, } \mathrm{mL} / \mathrm{d}\end{array}$ & $<1.2$ & $1.2-1.9$ & $2.0-3.4$ & $3.5-4.9$ or $<500$ & $>5.0$ or $<200$ \\
\hline
\end{tabular}

*Norad.- noradrenaline; Dob - dobutamine; Dop.- dopamine; $\mathrm{Adr}$ - adrenaline ; $\mathrm{FIO}_{2}$ - fraction of inspired oxygen

a. Values are with respiratory support

b. To convert bilirubin from $\mathrm{mg} / \mathrm{dL}$ to $\mu \mathrm{mol} / \mathrm{L}$, multiply by 17.1

c. Adrenergic agents administered for at least 1 hour (doses are given in $\mu \mathrm{g} / \mathrm{kg}$ per minute)

d. To convert creatinine from $\mathrm{mg} / \mathrm{dL}$ to $\mu \mathrm{mol} / \mathrm{L}$, multiply by 88.4

Modified from: Vincent JL1, Moreno R, TakalaJ, et al.The SOFA score to describe organ dysfunction / failure. On behalf of the Working Group on Sepsis-Related Problems of the ESICM: Intensive Care Med. 1996 Jul; 22(7): 707-10. 
The baseline SOFA score can be assumed to be zero in patients not known to have preexisting organ dysfunction.

A SOFA score $\geq 2$ reflects an overall mortality risk of approximately $10 \%$ in a general hospital population with suspected infection emphasizing the seriousness of this condition and the need for prompt intervention.

qSOFA (quick SOFA) - A simpler bedside tool to be used outside of ICU (since SOFA score is an ICU based mortality score). This score is expected to promptly identify patients with suspected infection who are likely to have a prolonged ICU stay or to die in the hospital.

- Septic shock is a subset of sepsis in which underlying circulatory and cellular/metabolic abnormalities are profound enough to substantially increase mortality.

Septic shock is identified with persisting hypotension requiring vasopressors to maintain the mean arterial pressure (MAP) $\geq 65 \mathrm{~mm} \mathrm{Hg}$ and with a serum lactate level $>2 \mathrm{mmol} / \mathrm{L}$ despite adequate volume resuscitation. These criteria are linked to a hospital mortality in excess of $40 \%{ }^{15}$.

It is noteworthy that there is no longer a condition called severe sepsis.

\section{qSOFAScore}

- Alteration in mental status

- Systolic blood pressure $\leq 100 \mathrm{~mm} \mathrm{Hg}$

- Respiratory rate $\leq 22 / \mathrm{min}$.

A score $\leq 2$ will identify patients who are likely to have poor outcomes.

\section{What are the limitations of Sepsis 3?}

SOFA and qSOFA scores are only predictors of mortality; neither diagnostic nor prognostic.

Reliance is on clinical suspicion in relation to the score. Moreover, SOFA is a complicated ICU scoring system that is not used globally. (e.g. many Australian ICUs use APACHE score instead).

qSOFA has neither been prospectively validated nor fully established. At the University of Chicago, USA a retrospective study carried out failed to validate the qSOFA score ${ }^{15}$. It was shown that qSOFA score has poor sensitivity and is a late indicator of clinical deterioration. The same study found that National Early Warning
Score (NEWS-recommended by NICE guidelines, UK Sepsis Trust, Royal College of Emergency Medicine) which uses data that is equally accessible at the bed side as a having better sensitivity and specificity ${ }^{17,18}$.

It is important to remember that despite these limitations, the initial definitions and guidelines resulted in global reduction in sepsis related morbidity and mortality ${ }^{11}$.

\section{Management}

Sepsis and septic shock being medical emergencies, warrant immediate resuscitation and treatment.

In 2001, Rivers et al published a single center RCT that described early goal directed therapy (EGDT) to improve the outcomes of sepsis ${ }^{19}$. Based on this trial, in 2004 the Surviving Sepsis Campaign (SSC) introduced the "bundle approach" to manage sepsis. What the SSC recommended was to have a protocolized quantitative resuscitation ${ }^{20}$. This guideline attracted widespread attention and improved global sepsis survival. Limitations of the Rivers study were subsequently highlighted.

The SSC guidelines were revised in 2008 and in 2012. Guidelines issued in 2012 described initial resuscitation in a "Three hour bundle" to be followed by a "Six hour bundle"21.

Three landmark clinical trials, ARISE, ${ }^{22}$ ProCESS ${ }^{23}$ and ProMISE ${ }^{24}$ compared mortality, clinical and cost outcomes of EGDT vs standard therapy. All trials found no advantage of EGDT over standard care in reducing mortality at 90 days. They did not demonstrate superiority of monitoring central venous pressure (CVP) and central venous oxygen saturation ( $\mathrm{ScvO} 2$ ) in patients with septic shock who received timely antibiotics and fluid resuscitation when compared to controls or those with serum lactate $>4 \mathrm{mmol} / \mathrm{L}$. It is noteworthy these trails did not demonstrate any harm caused by interventional strategies. The release of the updated guidelines of 2016 by SSC was after these trials ${ }^{25}$.

Three Hour Bundle (effective since 2012) includes -

1. Measurement of lactate

2. Obtaining blood cultures before antibiotic therapy

3. Administer broadspectrum antibiotics

4. Administer $30 \mathrm{ml} / \mathrm{kg}$ crystalloid for hypotension or lactate $\geq 4 \mathrm{mmol} / \mathrm{L}$

\section{Six Hour Bundle-}

1. Apply vasopressors for hypotension that remains unresponsive to initial fluid resuscitation aimed to maintain $\mathrm{MAP} \geq 65 \mathrm{mmHg}$ 
Table 2. Surviving sepsis campaign recommendation highlights

\begin{tabular}{|c|c|c|}
\hline & \\
\hline & 2012 & 2016 \\
\hline SepsisDefinition & $\begin{array}{l}\text { - Systemic manifestation of infection } \\
\text { (SIRS) + suspected or documented } \\
\text { infection } \\
\text { - Severe sepsis: sepsis + organ } \\
\text { dysfunction }\end{array}$ & $\begin{array}{l}\text { - Life threatening organ dysfunction } \\
\text { caused by dysregulated host response } \\
\text { to infection } \\
\text { - No severe sepsis category }\end{array}$ \\
\hline \multirow[b]{2}{*}{$\begin{array}{l}\text { Initial } \\
\text { Resuscitation }\end{array}$} & \multicolumn{2}{|c|}{$\begin{array}{l}\text { - At least } 30 \mathrm{ml} / \mathrm{kg} \text { in first } 3 \text { hours } \\
\text { - Crystalloid fluid (no recommendations on } 0.9 \% \text { NaClvs balanced solution) } \\
\text { - Albumin if patients require "substantial" fluids (weak) }\end{array}$} \\
\hline & $\begin{array}{l}\text { - Protocolized care including: } \\
\text { CVP } \\
\text { ScVO2 } \\
\text { - Normalize lactate }\end{array}$ & $\begin{array}{l}\text { - Use dynamic resuscitation markers } \\
\text { (passive leg raise) } \\
\text { - } \quad \text { Target MAP of } 65 \mathrm{mmHg} \\
\text { - } \quad \text { Reassess hemodynamic status to } \\
\text { guide resuscitation } \\
\text { - } \quad \text { Normalize lactate }\end{array}$ \\
\hline Vasopressors & \multicolumn{2}{|c|}{$\begin{array}{l}\text { - Target MAP of } 65 \mathrm{mmHG} \text { - } \\
\text { Noradrenaline - first line } \\
\text { Adrenaline if not at target MAP OR add vasopressin to reduce noradrenaline } \\
\text { requirement } \\
\text { Avoid dopamine in most patients }\end{array}$} \\
\hline Steroids & \multicolumn{2}{|c|}{$\begin{array}{l}\text { - Only indicated for patients with septic shock refractory to adequate fluids and } \\
\text { vasopressors }\end{array}$} \\
\hline Antibiotics & $\begin{array}{l}\text { - One or more antibiotics active } \\
\text { against presumed pathogen } \\
\text { - Combination therapy (double } \\
\text { coverage) for neutropenic patients } \\
\text { and pseudomonas }\end{array}$ & $\begin{array}{l}\text { Initial broad spectrum antibiotics (ex: } \\
\text { vancomycin + piperacillin- } \\
\text { tazobactam) } \\
\text { Against combined therapy (i.e. do not } \\
\text { double cover pseudomonas) } \\
\text { May use procalcitonin to guide } \\
\text { de-escalation }\end{array}$ \\
\hline Source民ontrol & - Achieve within 12 hours, if feasible & $\begin{array}{l}\text { - Achieve as soon as medically and } \\
\text { logistically feasible }\end{array}$ \\
\hline \multirow{3}{*}{ Ventilation } & \multicolumn{2}{|c|}{$\begin{array}{l}\text { - } 6 \mathrm{ml} / \mathrm{kg} \text { tidal volume in sepsis induced ARDS } \\
\text { - } \text { prone patients with severe ARDS (P/F <150 in } 2017 \text { guidelines) }\end{array}$} \\
\hline & - No recommendation & $\begin{array}{l}\text { - } \quad \text { Against high frequency oscillatory } \\
\text { ventilation (HFOV) }\end{array}$ \\
\hline & $\begin{array}{l}\text { Weak recommendation for non- } \\
\text { invasive ventilation in select } \\
\text { patients with sepsis induced } \\
\text { ARDS }\end{array}$ & $\begin{array}{l}\text { - Unable to make recommendation on } \\
\text { non-invasive ventilation }\end{array}$ \\
\hline
\end{tabular}

Modified from: Rhodes A, Evans LE, Ahzzani W et al. Surviving Sepsis Campaign: International Guidelines for Management of Sepsis and Septic Shock: 2016. Crit Care Med 2017; 1. 
2. In the event of persistent hypotension after initial fluid administration (MAP $<65 \mathrm{~mm} \mathrm{Hg}$ ) or if initial lactate was $\geq 4 \mathrm{mmol} / \mathrm{L}$, reassess volume status and tissue perfusion and document findings (as given below - a change from 2012 guidelines)

- Document reassessment of volume status and tissue perfusion with either; Repeat focused examination after initial fluid resuscitation including vital signs, cardiopulmonary, capillary refill, pulse, and skin findings.

Two of the following

- Measure CVP

- Measure ScvO2

- Bedside cardiovascular ultrasound

- Dynamic assessment of fluid responsiveness with passive leg raise or fluid challenge

\section{Remeasure lactate if initial lactate elevated}

The SSC guidelines do not cover every aspect of managing critically ill patients and their application should be supplemented by generic best practice and specific treatment as required.

Even though protocolized resuscitation recommended by the SSC has not shown to be superior to standard care in the ARISE ${ }^{23}$, ProCESS ${ }^{24}$ and ProMISE ${ }^{25}$ trials, one must bear in mind that all these trials were carried out in resource-rich settings. The majority of the participating hospitals were tertiary care or teaching facilities.

Available data on sepsis management of adults in resource-limited settings suggest that a high mortality is associated with ineffective management including delayed and improper empiric antimicrobial therapy as well as sub-optimal fluid resuscitation ${ }^{1,26}$.

Hence the authors of this article feel that a protocolized approach to sepsis management still plays a major role in improving outcomes in resource-limited settings.

\section{Therapeutic priorities in the management Initial resuscitation}

- All patients should receive supplemental oxygen. Stabilizing the airway and maintaining breathing must be addressed. If intubation is warranted it is important to use cardio stable drugs in doses that cause minimum haemodynamic changes.

- Early effective fluid resuscitation is crucial in sepsisinduced tissue hypoperfusion or septic shock. Hypotension is the most common sign of critical tissue hypoperfusion. Tissue hypoperfusion can also occur in the absence of hypotension, especially during early sepsis. Hence it is important to look for other signs of tissue hypoperfusion (e.g. confusion, reduced urine output).

- Resuscitation must aim to normalize lactate levels (since lactate is a marker of tissue hypoperfusion).

- As highlighted in SSC 3 hour bundle, up to $30 \mathrm{~mL} / \mathrm{kg}$ of intravenous crystalloid fluid can be given within the first 3 hours. Crystalloids are recommended as the fluid of choice. (e.g. balanced crystalloids or saline). Current guidelines do not state a difference in outcome between normal saline and balanced salt solutions. It is reasonable to use either type of fluid whilst being mindful of the side effects. (e.g. hypercholareamic metabolic acidosis when largevolumes of normal saline is used).

- Aditionally albumin (4-5\%) is recommended when patients require substantial amounts of fluids ${ }^{27}$. Use of hydroxyethyl starches is not recommended.

- Following initial resuscitation, additional fluids should be guided by frequent reassessment of hemodynamic status (see 6 hour bundle). This should include a thorough clinical examination for physical signs (capillary refill, heart rate, blood pressure, arterial oxygen saturation, respiratory rate, temperature, urine output and conscious level) as well as available non invasive or invasive monitoring.

- If the clinical examination yields no clear diagnosis, dynamic assessment of fluid responsiveness with passive leg raise or fluid challenge, bedside cardiovascular ultrasound, CVP and ScvO2 measurements are indicated.

- Fluid challenges are continued as long as hemodynamic parameters continue to improve.

- Once the patient becomes haemodynamically stable with no signs of tissue hypoperfusion, individualized and conservative fluid management should be ensured to prevent overloading.

\section{Vasopressors}

For patients in septic shock requiring vasopressors (hypotension or signs of tissue hypoperfusion after initial fluid resuscitation) the initial target MAP is $65 \mathrm{mmHg}$. Noradrenaline should be the vasopressor of choice. Adrenaline should be added if target MAP is not achieved. Vasopressin (up to $0.03 \mathrm{U} / \mathrm{min}$ ) can be added to reduce the dose of noradrenaline. Dopamine is not used as an alternative to noradrenaline except in highly selected patients such as those with inappropriately low heart rates (absolute or relative bradycardia) or at low risk for tachyarrhythmias. 


\section{Ionotropes}

A trial of dobutamine infusion up to 20 micrograms/ $\mathrm{kg} / \mathrm{min}$ may be administered or added to vasopressor in the presence of (a) myocardial dysfunction indicated by elevated cardiac filling pressures and low cardiac output, or (b) ongoing hypoperfusion (e.g. low CV oxygen saturation or high lactate) despite achieving adequate intravascular volume and MAP.

\section{Antimicrobial therapy}

Administration of intravenous antimicrobials must be initiated as soon as possible and definitely within one hour of the diagnosis. Blood and appropriate cultures must be obtained before starting antibiotics. Nevertheless, this must not delay the commencement of antimicrobials by more than one hour.

Empiric broad-spectrum therapy with one or more antimicrobials is recommended and de-escalated once sensitivities are established and/or adequate clinical improvement is noted. Please refer the guidelines issued by the Sri Lanka College of Microbiologists ${ }^{28}$.

The human cost of delaying effective antibiotic treatment is well established. The landmark study by Kumar et al in 2006 of 2,731 ICU based patients with septic shock in USA and Canada, showed a significant correlation between a delay in effective antibiotic therapy and in-hospital mortality ${ }^{29}$. This has been later corroborated by many other clinical trials ${ }^{30}$.

The inappropriate practice awaiting the next fixed drug delivery time to commence or to change antibiotics must be discouraged.

\section{Source control}

Once the diagnosis is made this must be implemented early when medically and logistically practical. Daily assessment and removal of unnecessary intravascular devices as possible sources of infection is vital and determines the degree of improved outcomes.

\section{Corticosteroids}

Intravenous hydrocortisone at a dose of $200 \mathrm{mg}$ per day is recommended only if adequate fluid resuscitation and vasopressor therapy are not able to restore hemodynamic stability.

\section{Glucose control}

It is recommended to maintain blood glucose levels $<180 \mathrm{mg} / \mathrm{dL}$ with insulin infusions.

\section{Mechanical ventilation}

In adult patients with sepsis-induced acute respiratory distress syndrome (ARDS), lung protective ventilatory strategies should be implemented.

Conservative fluid management should be used for patients with established sepsis-induced ARDS who do not have evidence of tissue hypoperfusion.

\section{Renal replacement therapy}

Continuous or intermittent renal replacement therapy (RRT) is indicated in patients with sepsis and acute kidney injury.

\section{Venous thromboembolism prophylaxis}

Pharmacologic and mechanical prophylaxis is recommended against venous thromboembolism (VTE) in the absence of contraindications.

\section{Stress ulcer prophylaxis}

This should be initiated inpatients with sepsis or septic shock who have risk factors for gastrointestinal bleeding.

\section{Nutrition}

As with any critically ill patient, administration of early parenteral nutrition is not recommended. Initiation of early hypocaloric enteral feeds to be advanced according to patient tolerance can be recommended.

\section{Setting goals of care}

Goals of care and prognosis should be discussed with patients and families. This should be incorporated into the treatment and end-of-life care planning.

\section{Conclusions}

- The reported incidence of sepsis is increasing. Morbidity and mortality rates are significant, as are costs to health systems around the globe.

- New definitions and management guidelines have been released with the aim of early diagnosis and escalation of management which is the key to improved outcomes.

- These definitions and guidelines will keep evolving as sepsis becomes better understood.

- Clinicians should be vigilant to ensure adherence to best practices when treating patients with sepsis. Several trials have shown that outcomes from standard care are comparable to those from protocolized quantitative resuscitation recommended by the SSC. However, it should be noted that these trials were 
performed in resource-rich settings. The protocolized approach may remain to be more suitable in resourcelimited settings as delays may occur with standard care in the initiation and management of sepsis.

\section{References}

1. Vincent JL, Marshall JC, Namendys-Silva SA, et al. ICON Investigators. Assessment of the worldwide burden of critical illness: the Intensive Care Over Nations (ICON) audit. Lancet Respir Med. 2014; 2(5): 380-86.

2. Fleischmann C, Scherag A, Adhikari NK, et al. International Forumof Acute Care Trialists. Assessment of global incidence and mortality of hospital-treated sepsis: current estimates and limitations. Am J Respir Crit Care Med. 2015; 193(3): 259-72.

3. NunnallyME, Sepsis for the anaesthetist, $\mathrm{Br} \mathrm{J}$ Anaesth 2016; 117(3): 44-51.

4. Torio CM, Andrews RM, National Inpatient Hospital Costs: The Most Expensive Conditions by Payer, 2011. in: Statistical Brief \#160. Healthcare Costand Utilization Project (HCUP) Statistical Briefs. 2013.

5. Kwan A, Hubank M, Rashid A, Klein N, Peters MJ. Transcriptional instability during evolving sepsis may limit biomarker based risk stratification. PLoS One. 2013; 8(3): e60501. Pub Med Article.

6. Iskander KN, Osuchowski MF, Stearns-Kurosawa DJ, et al. Sepsis: multiple abnormalities, heterogeneous responses, and evolving understanding. Physiol Rev. 2013; 93(3): 1247-288. Pub Med Article

7. Daniels R, Nutbeam T. The ABC of sepsis, 1st Ed, Chichester, West Sussex: Wiley-Blackwell; 2010.

8. Hauser $\mathrm{B}, \mathrm{Bracht} \mathrm{H}$, Matejovic M, et al. Nitric oxide synthase inhibition in sepsis? Lessons learned from large-animal studies. Anesth Analg. 2005; 101: 488-98.

9. Faust SN, Heyderman RS, Levin M. Coagulation in severe sepsis: a central role for thrombomodulin and active protein C. Crit Care Med. 2001; 29: S62-S68.

10. Abraham E, Singer M. Mechanisms of sepsis-induced organ dysfunction.Crit Care Med. 2007; 35: 2408-16.

11. Slesinger TL, Dubensky L. Sepsis - 3, a New Definition. Solutions or New Problems? ACEP quality improvement, patient safety section.

12. Bone RC, Balk RA, Cerra FB, et al. Definitions for sepsis and organ failure and guidelines for the use of innovative therapies in sepsis. The ACCP/SCCM Consensus Conference Committee. American College of Chest Physicians/ Society of Critical Care Medicine. Chest 1992 Jun; 101(6): 1644-55.

13. Kaukonen KM, Bailey M, Pilcher D, et al. Systemic in flammatory response syndrome criteria in defining severe sepsis. N Engl J Med 2015; 372: 1629-38.

14. Mitchell P, et al.2001 SCCM/ESICM/ACCP/ATS/SIS International Sepsis Definitions Conference. Intensive Care Med (2003) 29: 530-38.
15. Singer M, Deutschman CS, Seymour CW, et al. The third international consensus definitions for sepsis and septic shock (Sepsis-3). JAMA 2016; 315: 801-10.

16. Churpek MM, Snyder A, Han X, et al. qSOFA, SIRS, and Early Warning Scores for Detecting Clinical Deterioration in Infected Patients Outside the ICU. Am J Respir Crit Care Med. 2016; 315(8): 762-74.

17. Editorial. A national early warning score for acutely ill patients, BMJ 2012; 345: doi: https://doi.org/10.1136/ bmj.e5310 (Published 08 August 2012).

18. National early warning score (NEWS) - Standardising the assessment of acute-illness severity in the NHS, Report of a working party July 2012, Royal College of Physicians.

19. Rivers E, Nguyen B, Havstad S, et al. Early goal-directed therapy in the treatment of severe sepsis and septic shock. N Engl J Med 2001; 345: 1368-77.

20. Dellinger RP, Carlet JM, Masur H, et al. Surviving Sepsis Campaign guidelines for management of severe sepsis and septic shock. Crit Care Med. 2004; 32(3): 858-73.

21. Dellinger RP, Levy MM, Rhodes A, et al. Surviving Sepsis Campaign: international guidelines for management of severe sepsis and septic shock, 2012. Intensive Care Med 2013; 39:165-228.

22. ARISE investigators and the ANZICS clinical trials group. Goal-directed resuscitation for patients with early septic shock. N Engl J Med 2014; 371: 1496-506.

23. ProCESS Investigators. A randomized trial of protocolbased care for early septic shock. N Engl J Med 2014; 370: 1683-93.

24. Mouncey PR, Osborn TM, Power GS, et al. ProMISe Trial Investigators. Trial of early, goal directed resuscitation for septic shock. N Engl J Med 2015; 372: 1301-11.

25. Rhodes A, Evans IE, Alhazzani W, et al. Surviving Sepsis Campaign: International Guidelines for Management of Sepsis and Septic Shock: 2016, Critical Care Medicine 2017; 45(3): 486-552.

26. Jacob ST, Lim M, Banura $P$, et al. Integrating sepsis management recommendations into clinical care guidelines for district hospitals in resource-limited settings: the necessity to augment new guidelines with future research. BMC Medicine 2013; 11: 107.

27. NICE Guidelines on IV fluid therapy-CG 174), Updated Dec 2016.

28. Empirical and Prophylactic use of Antimicrobials - National Guidelines 2016, Sri Lanka College of Microbiologists.

29. Kumar A, Roberts D, Wood KE, et al. Duration of hypotension before initiation of effective antimicrobial therapy is the critical determinant of survival in humansepticshock. Crit Care Med 2006; 34: 1589-96.

30. Gaieski DF et al. Impact of time to antibiotics on survival in patients with severe sepsis or septic shock in whom early goal-directed therapy was initiated in the emergency department. Crit Care Med. 2010; 38 (4): 1045-53. 